\title{
Analysis of Saponins from Leaves of Aralia elata by Liquid Chromatography and Multi-stage Tandem Mass Spectrometry
}

\author{
Mingquan GuO, ${ }^{* \dagger}$ Lei ZHANG, ${ }^{* *}$ and Zhiqiang LIU* \\ *Changchun Institute of Applied Chemistry, Chinese Academy of Sciences, Changchun 130022, China \\ **College of Chemistry, Jilin University, Changchun 130021, China
}

\begin{abstract}
Four saponins were isolated from the leaves of Aralia elata, and established using NMR and other spectroscopic methods, as well as data reported in the literature. Three Aralia saponins from the leaves of Aralia elata sharing the same structures as those isolated from the root bark suggested that the leaves would be a good substitute for the root bark of Aralia elata. These four Aralia saponins were then extensively investigated using complementarily positive and negative electrospray ionization multistage tandem mass spectrometry $\left(E S I-M S^{n}\right)$. Two isomers of saponins with different sugar linkages were then successfully differentiated by positive ESI-MS ${ }^{\mathrm{n}}$ and verified with different retention times and the collision-induced dissociation (CID) spectra by LC-MS. A simple and effective LC-MS method was thus developed for the rapid identification and screening of these saponins in plant extracts from leaves of Aralia elata.
\end{abstract}

(Received August 13, 2008; Accepted October 6, 2008; Published June 10, 2009)

\section{Introduction}

Aralia elata is widely distributed in the northeast of China and Korea. Its root bark is used as a folk medicine for neurasthenia, rheumatism, diabetes, hepatitis virus, and spasm of the stomach in China, Japan, and Russia. It has been reported that triterpenoid saponins are the main active components. ${ }^{1}$ Many saponins have been isolated from the root bark of Aralia elata, and were reported to have anti-diabetic activity and cyto-protective effects on carbon tetrachloride-induced hepatic injury, ${ }^{2-6}$ which resulted in a devastating use of this herbal medicine. However, only a few studies on the saponins from leaves of Aralia elata were reported. ${ }^{7}$ To expand and protect the resources of this valuable medicinal plant, we initiated chemical and pharmacological investigations on saponin constituents from the leaves of Aralia elata.

The use of saponin fractions from Aralia elata also calls for detailed knowledge of the structures of Aralia saponins. The isolation and complete structural characterization of individual Aralia saponin are complicated and time-consuming tasks, requiring several chromatographic steps and combinations of chemical and spectroscopic techniques due to the inherent features of saponins, such as high polarity, non-volatility, and minute amounts in medicinal plants. Moreover, when the oligosaccharide chains of saponins become too complex, the NMR analysis of intact saponins may be more difficult, since the carbohydrate signals overlap extensively. Hence, it is impractical to perform full structural analysis on all of the components. Fortunately, most of the Aralia saponins are composed of certain structural elements (such as aglycone and oligosaccharide chain) that can be recognized without complete characterization. This feature

$\dagger$ To whom correspondence should be addressed.

Current address: University of Southern California, CA 90033, USA.

E-mail: mingquag@usc.edu enables a rapid and sensitive method for the structure characterization of saponin components in plant extracts and other preparations containing Aralia saponins by mass spectrometry.

Electrospray ionization multistage tandem mass spectrometry $\left(\right.$ ESI-MS $\left.^{\mathrm{n}}\right)$ has played an increasingly important role in the analysis of saponins over the past few years due to its high sensitivity, fast analysis speed, and low levels of sample consumption..$^{8-13}$ With ESI-MS $^{\mathrm{n}}$, not only can known ingredients in a mixture be rapidly identified, but also the structures of unknown saponins can be analyzed effectively. ${ }^{14,15}$ Previous publications demonstrated the powerfulness of ESI-MS ${ }^{\mathrm{n}}$ for the rapid and direct characterization of saponins in other plants. ${ }^{8,10,12,14,16-19}$ However, detailed mass spectrometric studies of saponins from Aralia elata have not been reported. On the other hand, ESI-MS ${ }^{\mathrm{n}}$ still has some trouble in identifying isomeric saponins in crude plant extracts. However, high-performance liquid chromatography as an efficient separation technique, when coupled with mass spectrometry, has been successfully introduced for the rapid analysis of non-volatile compounds (including saponins) in crude plant extracts. ${ }^{20-23}$ Here, we reported on an extensive investigation of a set of Aralia saponins firstly isolated from leaves of Aralia elata by ESI-MS ${ }^{\mathrm{n}}$. Some diagnostic key fragment ions that are important for the structure elucidation of Aralia saponins were characterized. The spectra were acquired in both positive and negative ion modes for the selected fragmentation route up to $\mathrm{MS}^{5}$. Two isomeric saponins from leaves of Aralia elata, which can not be differentiated by negative ESI-MS ${ }^{\text {, }}$, can be successfully identified by positive ESI$\mathrm{MS}^{\mathrm{n}}$. Because of the isomeric saponins existing in the leaves of Aralia elata, ESI-MS ${ }^{\mathrm{n}}$ can not be used for the direct analysis of the isomeric saponins in mixtures from crude plant extracts. An efficient HPLC-MS method has been successfully developed for the direct characterization of saponin in crude extracts from leaves of Aralia elata, thus avoiding time-consuming and materialconsuming efforts in phytochemistry separation. Furthermore, the differentiation of two isomeric saponins by positive ESI-MS ${ }^{\mathrm{n}}$ was 
confirmed by HPLC-MS using in-source collision-induced dissociation (CID).

\section{Experimental}

\section{Materials}

Leaves of Aralia elata were collected at Ji'an city of Jilin province in China, and these botanical sources were identified by Professor G. S. Wang from the college of medicine of Jilin University, where a voucher specimen had been deposited. OuyaR18 TLC plate was obtained from Swiss. D101 macro-porous absorption resin was purchased from Chemical Engineering Factory of Tianjin Nankai University. TLC silica-gel H/T 235492 was purchased from Qingdao Ocean Chemical Engineering Inc. Hypersil C18 column $(250 \mathrm{~mm} \times 4.6 \mathrm{~mm}$ i.d.; particle size, $5 \mu \mathrm{m})$ was purchased from Dalian Yi Li Te Co. (China). All of the solvents used were of analytical purity.

\section{Extraction and isolation}

Dried leaves $(1 \mathrm{~kg})$ of Aralia elata were extracted three times with methanol $(2$ l) for $20 \mathrm{~min}$ with ultra-sonication, and the combined extracts were concentrated to syrup under reduced pressure, then suspended in water. The suspension was extracted with petroleum ether, chloroform, and 1-butanol saturated with water, successively, to give the respective extract after removal of the solvent. The 1-butanol-soluble part was subjected to a D101 macro-porous absorption resin column, and the column was then successively eluted with $\mathrm{H}_{2} \mathrm{O}$ and ethanol. The ethanol eluates were collected and $13 \mathrm{~g}$ powder residues were obtained after removal of the solvent under reduced pressure. Part of the residues $(2 \mathrm{~g})$ were repeatedly chromatographed on silica columns (100 mm $\times 10 \mathrm{~mm}$ i.d., $180-200$ mesh silica), eluting successively with (a) $\mathrm{CHCl}_{3}-\mathrm{MeOH}-\mathrm{EtOAc}-\mathrm{H}_{2} \mathrm{O}$ (15:22:40:10, v/v/v/v, lower phase); (b) $\mathrm{CHCl}_{3}-\mathrm{MeOH}-\mathrm{H}_{2} \mathrm{O}$ (65:35:10, v/v/v, lower phase), and (c) $\mathrm{BuOH}-\mathrm{EtOAc}-\mathrm{H}_{2} \mathrm{O}(4: 1: 2, \mathrm{v} / \mathrm{v} / \mathrm{v}$, upper phase). The eluates were monitored by TLC silica-gel after spraying with a $10 \% \mathrm{H}_{2} \mathrm{SO}_{4}$ solution. The fractions containing the same compound were combined and concentrated until only one spot was detected by all of the three solvent systems under (a) - (c) using the TLC plate to afford compounds $\mathbf{1}(37 \mathrm{mg}), \mathbf{2}(43 \mathrm{mg}), \mathbf{3}(56 \mathrm{mg})$ and 4 (26 mg).

\section{NMR experiment}

${ }^{13} \mathrm{C}$-NMR spectra were recorded on a Bruker DRX 500 spectrometer. Compounds $\mathbf{1 - 4}$ were dissolved in $\mathrm{CDCl}_{3}$ separately. TMS was used as an internal standard.

\section{LC conditions}

An Agilent 1100 series HPLC system equipped with a quaternary pump, a degasser, a thermostatic auto-sampler and a photodiode array detector (DAD), was used for the analysis of saponin extracts from leaves of Aralia elata. The analysis was carried out with a Hypersil C18 column $(250 \mathrm{~mm} \times 4.6 \mathrm{~mm}$ i.d., particle size $5 \mu \mathrm{m}$ ). The binary mobile phase consisted of $30 \%$ acetonitrile, $70 \% \mathrm{H}_{2} \mathrm{O}$, and $0.1 \%$ formic acid. All solvents were filtered through a $0.45-\mu \mathrm{m}$ filter prior to use. The flow rate was kept at $1.0 \mathrm{ml} / \mathrm{min}$ for a total run time of $1 \mathrm{~h}$. The sample injection volume was $10 \mu \mathrm{l}$. Peaks of interest were monitored at $208 \mathrm{~nm}$ by the HPLC detector.

\section{ESI-MS ${ }^{n}$ and LC/MS/MS experiments}

Mass spectrometry experiments were performed on a LCQ ion trap instrument (Finnigan MAT, San Jose, CA) with an electrospray ion source. Compounds $\mathbf{1 - 4}$ were dissolved in
$\mathrm{MeOH}$ and introduced via a syringe pump at a flow rate of $3 \mu \mathrm{l} / \mathrm{min}$, respectively. The ion gauge pressure was $2.4 \times 10^{-5}$ Torr. Nitrogen was used as sheath gas at a pressure of 100 psi. For $\mathrm{MS}^{\mathrm{n}}$ experiments, the mass window for the parent ion selection was 2.0Th. Helium was used as the collision gas, and the collision energy was adjusted until the intensity ratio of the base peak to the parent ion between 2 and 20. The electrospray voltage was set at $5.0 \mathrm{kV}$ for the positive-ion mode and $-5 \mathrm{kV}$ in the negative-ion mode. The capillary temperature was set to $200^{\circ} \mathrm{C}$. As for HPLC/MS experiments, the Agilent 1100 series HPLC system described above was coupled to a mass spectrometer via a UV cell outlet. The HPLC/MS/MS samples were prepared as follows: dry leaves of Aralia elata $(1 \mathrm{~g})$ were immersed in $100 \mathrm{ml}$ of $\mathrm{MeOH}$ and extracted by ultrasonication for $1 \mathrm{~h}(3$ times, each time for $20 \mathrm{~min}$ ) at room temperature. The combined $\mathrm{MeOH}$ extracts were dissolved with $50 \mathrm{ml}$ of $\mathrm{H}_{2} \mathrm{O}$ after removal of $\mathrm{MeOH}$. The extraction of saponins was performed with 1-butanol. The 1-butanol layer was merged, centrifuged, and evaporated under reduced pressure. The crude saponin residues were subjected to a D101 macro-porous absorption resin column after being filtered, and then eluted successively with $\mathrm{H}_{2} \mathrm{O}$ and ethanol. The ethanol eluate was collected and a powder residue was obtained after removing the solvent under reduced pressure; then, the residue was dissolved in $100 \mu \mathrm{l}$ of methanol and filtered through a $0.45-\mu \mathrm{m}$ filter before LC/MS analyses.

\section{Nomenclatures for fragment ions of saponins}

In order to elucidate the fragment pathways of saponins from leaves of Aralia elata, fragment ions were labeled according to nomenclature proposed by Domon and Costello. ${ }^{24}$ The ions retaining the charge on the part containing the aglycone were termed X (cross-ring cleavages), $\mathrm{Y}$ and $\mathrm{Z}$ (glycosidic cleavages) ions, where those retaining the charge on the sugar moieties were termed A (cross-ring cleavages), B and C (glycosidic cleavages) ions. Cross-ring cleavage ions were also designated by superscript numbers, indicating where the two bonds cleaved. In this study, the saccharide chain at $\mathrm{C}-3$ of the aglycone was labeled as an $\alpha$-chain, and that at $\mathrm{C}-28$ of the aglycone was termed a $\beta$-chain; the branching chain derived from the $\alpha$-chain was termed an $\alpha_{1}$-chain.

\section{Results and Discussion}

\section{Identification of compound $\mathbf{1}$ - $\mathbf{4}$}

The structures of the four saponins isolated from leaves of Aralia elata were established on the basis of chemical and spectral evidence, as well as data reported in the literature. Taking compound $\mathbf{1}$ as an example, in ESI-MS spectra, a predominated peak at $\mathrm{m} / \mathrm{z} 1127$ corresponding to $[\mathrm{M}+\mathrm{Na}]^{+}$in the positive-ion mode, and a peak at $m / z 1103$, assigned as $[\mathrm{M}-\mathrm{H}]^{-}$in the negative mode, were observed, which confirmed that the molecular weight of compound 1 was 1104.

Based on negative ESI-MS ${ }^{\mathrm{n}}$ data, compound $\mathbf{1}$ was proposed to consist of three glucoses and an aglycone with a mass of 456 (details shown later). It rapidly gave us an overall idea of the structure of compound $\mathbf{1}$. To identify compound $\mathbf{1}$ from scratch, it was very useful that the NMR data of compound $\mathbf{1}$ could be quickly assigned for complete structure elucidation. The NMR data were found (data not shown) to be in very good agreement with the saponin (Aralia saponin V) isolated from root bark of Aralia elata, which was reported by Song et al. ${ }^{5}$ In this way, all of the other three saponin from leaves of Aralia elata were identified. Compound $\mathbf{2}$ corresponds to the saponin (Congmunoside X) isolated from the root bark of Aralia elata. ${ }^{25}$ 

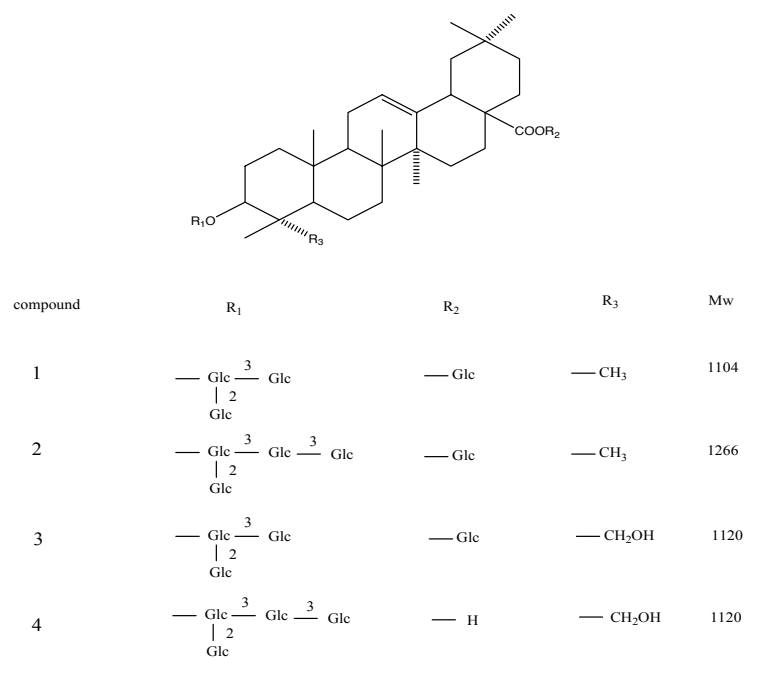

Fig. 1 Structures of triterpenoid saponins from leaves of Aralias elata.

Compound $\mathbf{3}$ was assigned as Aralia saponin from the root bark of Aralia elata, ${ }^{5}$ and compound $\mathbf{4}$ was consistent with Congmunoside B. ${ }^{7}$ The structures of compounds $\mathbf{1}-\mathbf{4}$ are shown in Fig. 1. These saponins from the leaves of Aralia elata shared the same chemical structures as the saponins from the root bark of Aralia elata, which suggested that the leaves might be used as a good substitute for the root bark of Aralia elata, based on the active saponin components, and can thus avoid the devastating use of root bark of this valuable plant.

\section{Negative ESI-MS ${ }^{n}$ of compounds 1 - 4}

Saponins could be analyzed by ESI-MS ${ }^{\mathrm{n}}$ in both the positive and negative ion modes. ${ }^{11,23,26,27}$ Here, an extensive investigation on a set of Aralia saponins by both negative and positive ESI$\mathrm{MS}^{\mathrm{n}}$ was conducted. Negative ESI-MS ${ }^{\mathrm{n}}$ spectra of saponins had the main advantage in outlining the structures of saponins.

As shown in Fig. 1, compounds $\mathbf{1}-\mathbf{4}$ possessed a common basic structure consisting of a triterpenoidic core, substituted with different sugar moieties at C-3 by an ether linkage ( $\alpha$-chain) and/or at $\mathrm{C}-28$ by an ester linkage ( $\beta$-chain). The fragmentation pathways of saponin in the negative ion mode showed exclusive signals corresponding to cleavage of the glycosidic bonds, which allowed a straight-forward interpretation of the spectra. Direct information on the sugar composition and the mass of the aglycone (sapogenin) could be easily obtained, which greatly facilitated a completely structural elucidation from scratch. Representative negative ESI-MS ${ }^{\mathrm{n}}$ spectra of compound $\mathbf{1}$ are shown in Fig. 2. Figures 2(a) - 2(d) exhibited sequential mass losses of $162 \mathrm{Da}$, indicating a sequential loss of glucose residues; all of these product ions were attributed to $\mathrm{Y}$ type of ions $\left(\mathrm{Y}_{0}, \mathrm{Y}_{1}\right.$, or $\mathrm{Y}_{2}$ ). Taken together, $\mathrm{MS}^{2}-\mathrm{MS}^{5}$ in Fig. 2, there were four glucoses in compound $\mathbf{1}$, and the ion at $\mathrm{m} / \mathrm{z} 455$ (Fig. 2(d)) could not be further fragmented, which suggested a relatively stable structure in compound $\mathbf{1}$, indicating the possibility of an aglycone of compound 1. The ion at $m / z 455$ was also in good agreement with $[\mathrm{M}-\mathrm{H}]^{-}$of oleanolic acid $\left(M_{\mathrm{W}}=456\right)$. This triterpenoidic type of aglycone had been reported to exist in this plant. ${ }^{5}$ It was therefore made clear that compound $\mathbf{1}$ consisted of an oleanolic acid as the aglycone and four glucose residues. However, the linkages between the sugars and the aglycone could not be resolved only by negative ESI-MS ${ }^{\mathrm{n}}$. However, compounds 2 - 4 could be easily outlined using negative ESI-MS ${ }^{\mathrm{n}}$; the negative
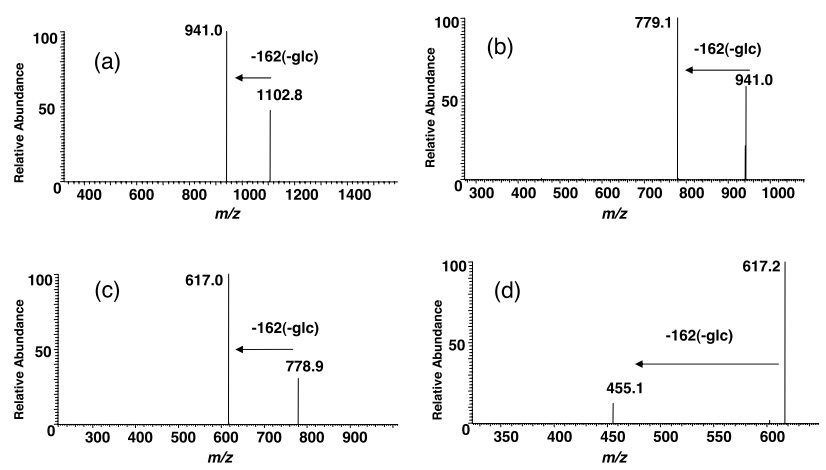

Fig. 2. Negative $M^{n}$ spectra of compound 1. (a) MS/MS spectrum of $[\mathrm{M}-\mathrm{H}]^{-}$ion of compound $\mathbf{1}$ at $\mathrm{m} / \mathrm{z}, 1103$, (b) $\mathrm{MS}^{3}$ spectrum of the ion at $m / z, 941$ from the $[\mathrm{M}-\mathrm{H}]^{-}$ion of compound 1, (c) $\mathrm{MS}^{4}$ spectrum of the ion at $\mathrm{m} / z 779$ from the $[\mathrm{M}-\mathrm{H}]^{-}$ion of compound $\mathbf{1}$, (d) $\mathrm{MS}^{5}$ spectrum of the ion at $m / z 617$ from the $[\mathrm{M}-\mathrm{H}]^{-}$ion of compound $\mathbf{1}$.

Table 1 Key fragment ions observed in the negative ESI-MS spectra of compounds $\mathbf{1}-\mathbf{4}$

\begin{tabular}{|c|c|c|c|c|c|c|c|}
\hline & {$[\mathrm{H}-\mathrm{M}]^{-}$} & $\mathrm{MS}^{2}$ & & $\mathrm{MS}^{3}$ & & $\mathrm{MS}^{4}$ & $\mathrm{MS}^{5}$ \\
\hline & -162 & & -162 & & -162 & -162 & \\
\hline 1 & $1103 \longrightarrow$ & 941 & & -779 & $\longrightarrow$ & -617 & -455 \\
\hline \multirow{3}{*}{2} & $1265-162$ & 1103 & -162 & 941 & -162 & 779 & \\
\hline & & & $-162 * 2$ & -779 & -162 & $617-162$ & 455 \\
\hline & & & $-162 * 3$ & -617 & -162 & & \\
\hline \multirow{3}{*}{3} & $1119-162$ & 957 & -162 & -795 & -162 & 633 & \\
\hline & & & $-162 * 2$ & 633 & $\underline{-162}$ & 471 & \\
\hline & $-162 *$ & 795 & -162 & -633 & -162 & 471 & \\
\hline \multirow[t]{3}{*}{4} & $11199^{-162}$ & 957 & -162 & -795 & -162 & 633 & \\
\hline & & & $-162 * 2$ & 633 & $\underline{-162}$ & 471 & \\
\hline & -162 & 795 & -162 & -633 & -162 & 471 & \\
\hline
\end{tabular}

*, Stands for "multiplied by" in both Tables 1 and 2 .

ESI-MS $^{\mathrm{n}}$ data for compounds $\mathbf{1} \mathbf{- 4}$ are summarized in Table 1. From Table 1, the following information could be easily collected: compound $\mathbf{2}$ was made up of an oleanolic acid aglycone and five glucose residues; compounds $\mathbf{3}$ and $\mathbf{4}$ exhibiting the same negative ESI-MS $^{n}$, were comprised of an aglycone with a mass of 472 and four glucose residues. The aglycone with a mass of 472 corresponded to hederagenin in this plant. ${ }^{5,7}$ The isomers of compounds $\mathbf{3}$ and $\mathbf{4}$ could not be differentiated at this point, while both positive ESI-MS ${ }^{n}$ and HPLC/MS could be used to differentiate them.

\section{Positive ESI-MS ${ }^{n}$ of compounds 1 - 4}

Negative ESI-MS ${ }^{\mathrm{n}}$ could outline the structures of saponins, but it had limitations in exploring more structural information on saponins, such as linkages between sugars and aglycones, linkages among sugars, and differentiation of isomeric saponins. However, positive ESI-MS ${ }^{\mathrm{n}}$ could be used to determine isomeric saponins, and even some information on the linkages among sugars. ${ }^{28,29}$ Representative positive ESI-MS ${ }^{n}$ spectra of compound $\mathbf{1}$ are shown in Fig. 3. Figure 3(a) shows the $\mathrm{MS}^{2}$ spectrum of the $\mathrm{m} / \mathrm{z}$ $1127[\mathrm{M}+\mathrm{Na}]^{+}$ion. $[\mathrm{M}+\mathrm{Na}]^{+}$produced only the $\mathrm{Y}$ type of fragment ion at $m / z, 965\left(\mathrm{Y}_{0 \beta}\right)$, representing a glycosidic cleavage at C-28 by the loss of a glucose residue (162), due to the presence 

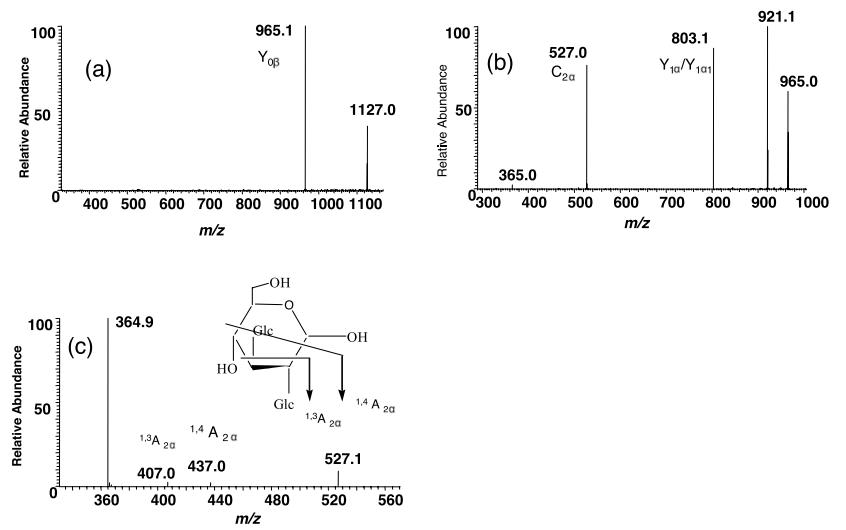

Fig. 3 Positive $\mathrm{MS}^{\mathrm{n}}$ spectra of compound 1. (a) MS/MS spectrum of the $[\mathrm{M}+\mathrm{Na}]^{+}$ion of the compound at $m / z, 1127$, (b) $\mathrm{MS}^{3}$ spectrum of the ion at $m / z, 965$ from the $[\mathrm{M}+\mathrm{Na}]^{+}$ion of compound 1, (c) MS $\mathrm{MS}^{4}$ spectrum of the ion at $\mathrm{m} / z, 527$ from the $[\mathrm{M}+\mathrm{Na}]^{+}$ion of compound $\mathbf{1}$.

of an acetyl group in compound $1 .^{29} \mathrm{MS}^{3}$ of the $\mathrm{m} / \mathrm{z}, 965$ ion in Fig. 3(b) further confirmed the assignment.

There were two pieces of evidences indicating the neutral loss of a glucose residue from C-28 of the aglycone. The $m / z, 965$ ion produced fragment ions at $\mathrm{m} / \mathrm{z} 921\left(-\mathrm{CO}_{2}\right), 803\left(\mathrm{Y}_{1 \alpha} / \mathrm{Y}_{1 \alpha 1}\right), 527$ $\left(\mathrm{C}_{2} \alpha\right)$ and $365\left(\mathrm{C}_{2} \alpha\right)$. The mass differences between the fragment ions at $\mathrm{m} / \mathrm{z}, 921$ and 803 and the precursor ion at $\mathrm{m} / \mathrm{z}, 965$ are 44 and $162 \mathrm{Da}$, respectively. The mass loss of $44 \mathrm{Da}$ was consistent with the loss of $\mathrm{CO}_{2}$, which provided the first evidence indicating the loss of a glucose residue from $\mathrm{C}-28$ of the aglycone. Because a loss of the glucose residue from $\mathrm{C}-28$ led to the formation of unstable tert-C-COOH, it is easy to eliminate $\mathrm{CO}_{2}$ from this structure under CID conditions; and the mass loss of 162 Da was indicative of the loss of a glucose residue. The product ion at $\mathrm{m} / \mathrm{z} 527$ was more important and informative, which provided the second proof indicating the loss of a glucose residue from C-28 of the aglycone and the information about the linkage between sugars residues. The ion at $\mathrm{m} / \mathrm{z}, 527$ corresponded to sodiated $\mathrm{C}_{3}-$ trisaccharide, which provided very helpful information suggesting the existence of a trisaccharide residue attached to the aglycone of compound 1 that could not be obtained from negative ESI-MS data. On the other hand, the $m / z, 527$ ion suggested that the ion at $\mathrm{m} / \mathrm{z}, 965$ belonged to $\mathrm{Y}_{0 \beta}$, because if the neutral loss of the glucose residue were from the trisaccharide chain, the ion at $\mathrm{m} / \mathrm{z} 527$ should not be observed. By combining data from both positive and negative ESI-MS ${ }^{\mathrm{n}}$, the structure of compound $\mathbf{1}$ have now become more clear, compound $\mathbf{1}$ consists of C-3 trisaccharide (glucoses), a C-28 glucose and an oleanolic acid as triterpenoid aglycone. However, structural details on $\mathrm{C}_{3}$-trisaccharide, such as the linkages between these three glucoses, remained unknown.

To investigate the structure of the $m / z 527\left(\mathrm{C}_{2} \alpha\right)$ ion further, $\mathrm{MS}^{4}$ experiments were performed, and the proposed fragmentation is illustrated in Fig. 3(c). The ion at $\mathrm{m} / \mathrm{z} 527$ yielded three fragment ions: the $\mathrm{Y}_{1 \alpha} / \mathrm{Y}_{1 \alpha 1}$ ion at $\mathrm{m} / \mathrm{z} 365$ by the loss of one glucose residue, a series of cross-ring ions, ${ }^{1,4} \mathrm{~A}_{2 \alpha}$, at $\mathrm{m} / \mathrm{z}, 437$ and ${ }^{1,3} \mathrm{~A}_{2 \alpha}$ at $\mathrm{m} / \mathrm{z}$ 407. These two cross-ring ions indicate that one glucose residue linked with the reducing terminal glucose at position 2, and the other glucose residue linked with the reducing terminal glucose at position 3 . It was known that all of the crossring ions ( $\mathrm{X}$ and $\mathrm{A}$ types of ions) were derived from the crossring reactions of the sugar unit at the reducing end, and that the linkage positions between the sugar residues affected the crossring fragmentations of their precursor ions. These characteristic fragment ions can thus provide very important sugar linkage
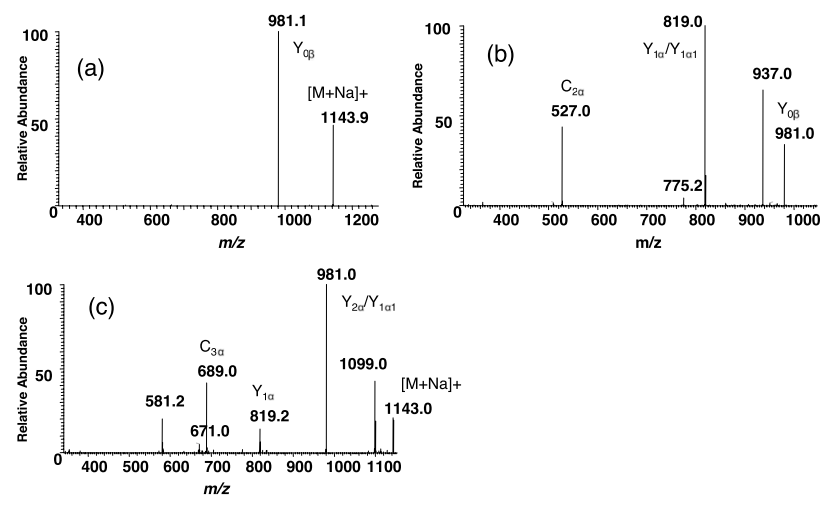

Fig. 4 Positive $\mathrm{MS}^{\mathrm{n}}$ spectra of compounds 3 and 4. (a) MS/MS spectrum of the $[\mathrm{M}+\mathrm{Na}]^{+}$ion of compound 3 at $\mathrm{m} / \mathrm{z}$ 1143, (b) $\mathrm{MS}^{3}$ spectrum of the ion at $\mathrm{m} / \mathrm{z}, 981$ from the $[\mathrm{M}+\mathrm{Na}]^{+}$ion of compound $\mathbf{3}$, (c) MS/MS spectrum of the $[\mathrm{M}+\mathrm{Na}]^{+}$ion of compound 4 at $\mathrm{m} / z, 1143$.

information. No $\mathrm{H}_{2} \mathrm{O}$ loss ion in Fig. 3(c) was observed, indicating that there must be a branched glucose residue at the $\mathrm{C}-2$ position of the reducing terminal glucose, or else $\mathrm{m} / \mathrm{z} 509$ should be observed in the spectra. This conclusion can be easily drawn from a comparison between the fragmentation patterns of disaccharides Sophorose (1-2 linkage) and Cellobiose (1-4 linkage) as we previously reported. ${ }^{18}$ A series of cross-ring ions, ${ }^{1,4} \mathrm{~A}_{2 \alpha}$ at $m / z, 437$ and ${ }^{1,3} \mathrm{~A}_{2 \alpha}$ at $m / z, 407$, not only further confirmed our deduction that $\mathrm{C}-2$ of the reducing terminal glucose was substituted by a glucose residue, but also indicated there were two substitutions of glucose residues linked with the reducing terminal glucose, because if only one position $(\mathrm{C}-2)$ had been substituted, the fragment ions should be different from what had been observed. Observations of the ${ }^{1,4} \mathrm{~A}_{2 \alpha}$ ion at $\mathrm{m} / \mathrm{z}, 437$ and ${ }^{1,3} \mathrm{~A}_{2 \alpha}$ ion at $m / z 407$ indicated that the two substitutions of glucose residues should be in the neighboring positions. Since we confirmed one glucose residue at $\mathrm{C}-2$ of the reducing end, the other glucose residue should be linked at $\mathrm{C}-3$ of the reducing end. These proposed linkages within the trisaccharides were in good agreement with the experimental data. By now, more structural information about compound 1 can be proposed as glc(1-2) [glc(13)]-glc-(C-3)A1(C-28)-glc (here, A1 stands for aglycone of compound 1; later, A2, A3, and A4 represent the aglycone of compounds 2, 3 and 4, respectively). However, the stereochemistry and the exact structure could not be deduced from the mass spectra; this structural information will be very helpful in the rapid characterization of saponins, or the prediction of novel saponin structures with higher sensitivity than that of any other method.

Positive ESI-MS ${ }^{\mathrm{n}}$ experiments were also found to be very useful in the differentiation of some isomeric saponins from the leaves of Aralia elata. Negative ESI-MS ${ }^{\mathrm{n}}$ experiments on compounds 3 and 4 showed the same results (as shown in Table 1). However, positive ESI-MS ${ }^{\mathrm{n}}$ experiments exhibited obvious differences. Positive ESI-MS ${ }^{\mathrm{n}}$ spectra are shown in Fig. 4. By comparing the $\mathrm{MS}^{2}$ spectra of compound $\mathbf{3}$ with that of compound $\mathbf{4}$, these two isomers could be easily differentiated. In the mass spectrum of compound 3 (Fig. 4(a)), the only fragment ion observed at $\mathrm{m} / \mathrm{z}$ 981 was attributed to the $\mathrm{Y}_{0 \beta}$ ion, because the loss of the C-28 esterified glucose residue was favored. ${ }^{14,16,29}$ The $\mathrm{MS}^{3}$ spectrum of compound 3 further confirmed these assignments. The $\mathrm{Y}_{0 \beta}$ ion at $\mathrm{m} / \mathrm{z}, 981$ yielded three main fragment ions at $\mathrm{m} / \mathrm{z}, 937,819$, and 527. The ion at $\mathrm{m} / \mathrm{z}, 937$ corresponded to a neutral loss of $\mathrm{CO}_{2}$. The ion at $m / z, 819\left(\mathrm{Y}_{1 \alpha} / \mathrm{Y}_{1 \alpha 1}\right)$ was consistent with the loss of one glucose residue from the $\mathrm{C}-3$ oligosaccharide chain. The $\mathrm{C}_{2 \alpha}$ ion 
Table 2 Key fragment ions observed in the positive ESI-MS ${ }^{n}$ spectra of compounds 1 - 4

\begin{tabular}{|c|c|c|c|c|c|c|c|}
\hline & {$[\mathrm{H}+\mathrm{M}]^{+}$} & $\mathrm{MS}^{2}$ & MS & & $\mathrm{MS}^{4}$ & & $\mathrm{MS}^{5}$ \\
\hline \multirow[t]{6}{*}{1} & $1127 \stackrel{-162}{\longrightarrow}$ & 965 & $\stackrel{-44}{\longrightarrow} 921$ & -162 & -759 & & \\
\hline & & & & -394 & -527 & & \\
\hline & & & $-162 \longrightarrow 803$ & -162 & -365 & & \\
\hline & & & $-438-527$ & -90 & -137 & & \\
\hline & & & $\stackrel{-600}{\longrightarrow} 365$ & -120 & -407 & & \\
\hline & & & & -162 & -921 & & \\
\hline \multirow[t]{9}{*}{2} & $1289 \stackrel{-162}{\longrightarrow}$ & 1127 & $\stackrel{-44}{\longrightarrow} 1083$ & -394 & -689 & & \\
\hline & & & -162 & -556 & -527 & & \\
\hline & & & $\underset{-324}{\longrightarrow} 965$ & -162 & -921 & & \\
\hline & & & $\longrightarrow 803$ & -206 & -803 & & \\
\hline & & & & -438 & -527 & -18 & -509 \\
\hline & & & -438 & -162 & 527 & -60 & 509 \\
\hline & & & & -324 & -365 & -90 & $\begin{array}{r}-437 \\
\end{array}$ \\
\hline & & & $-600 \longrightarrow 527$ & & & -120 & -407 \\
\hline & & & $\stackrel{-44}{\longrightarrow} 037$ & -44 & 775 & -162 & -365 \\
\hline \multirow{6}{*}{3} & $1143-162$ & 981 & -162 & -162 & $1 / 13$ & & \\
\hline & & & -206 & -454 & 265 & & \\
\hline & & & $-454 \longrightarrow$ & -162 & -365 & & \\
\hline & & & & -90 & 437 & & \\
\hline & & & & -120 & -407 & & \\
\hline & & & -162 & -162 & tor & & \\
\hline \multirow{12}{*}{4} & $1143-44$ & 1099 & $-324 \stackrel{-}{\longrightarrow} 775$ & -198 & -739 & & \\
\hline & & & $\stackrel{-428}{\longrightarrow} 671$ & -366 & 571 & & \\
\hline & & & $\stackrel{-410}{\longrightarrow} 689$ & -410 & -527 & & \\
\hline & -162 & 981 & $-44 \longrightarrow 937$ & -428 & 509 & & \\
\hline & & & $\stackrel{-162}{\longrightarrow} 819$ & & & & \\
\hline & $\stackrel{-162 * 2}{\longrightarrow}$ & 819 & $\stackrel{-206}{\longrightarrow} 775$ & & & & \\
\hline & & & $\stackrel{-162 * 2}{\longrightarrow} 657$ & & & & \\
\hline & & & -454 & -18 & 500 & & \\
\hline & -454 & & $-162-507$ & -60 & 160 & & \\
\hline & & & $-324-365$ & -90 & 127 & & \\
\hline & $\stackrel{-562}{\longrightarrow}$ & 581 & & -120 & 407 & & \\
\hline & & & & -162 & & & \\
\hline
\end{tabular}

at $\mathrm{m} / \mathrm{z}, 527$ provided direct evidence of the C-3 oligosaccharide, which was consistent with the sodiated triasaccharide. However, regarding the $\mathrm{MS}^{2}$ spectrum of compound 4 (Fig. 4(c)), five abundant peaks were shown at $\mathrm{m} / \mathrm{z}, 1099,981,819,689$, and 581 . The ion at $\mathrm{m} / \mathrm{z} 1099$ corresponded to a neutral loss of $\mathrm{CO}_{2}$, indicating that no sugar residues were linked with $\mathrm{C}-28$ of the aglycone. A series of $\mathrm{Y}$ ions at $m / z 981\left(\mathrm{Y}_{2 \alpha} / \mathrm{Y}_{1 \alpha 1}\right)$ and $819\left(\mathrm{Y}_{1 \alpha}\right)$ were consistent with the loss of one or two glucose residues from the C-3 oligosaccharide chain, respectively. The $\mathrm{C}_{3 \alpha}$ ion at $\mathrm{m} / \mathrm{z}$ 689 provided direct evidence of the C-3 oligosaccharide, which is consistent with the sodiated tetrasaccharide. Thus, the isomeric saponins, compounds $\mathbf{3}$ and $\mathbf{4}$, were successfully differentiated by positive ESI-MS ${ }^{\mathrm{n}}$ methods.

The positive ESI-MS ${ }^{\mathrm{n}}$ data for compounds $\mathbf{1}-\mathbf{4}$ are summarized in Table 2. The structures of compounds $\mathbf{1}-\mathbf{4}$ could be readily proposed: compound 1 corresponding to glc(1-3)[glc(1-2)]-glc(C-3)A1(C-28)-glc; compound 2 being in good agreement with glc(1-3)[glc(1-2)]-glc(1-3) glc-(C-3)A2(C-28)-glc; compound 3 assigned as glc(1-3)[glc(1-2)]-(C-3)A3(C-28)-glc; and compound 4 corresponding to $\operatorname{glc}(1-2)[\mathrm{glc}(1-3)]-\mathrm{glc}(1-3)-(\mathrm{C}-3) \mathrm{A} 4(\mathrm{C}-28)$.

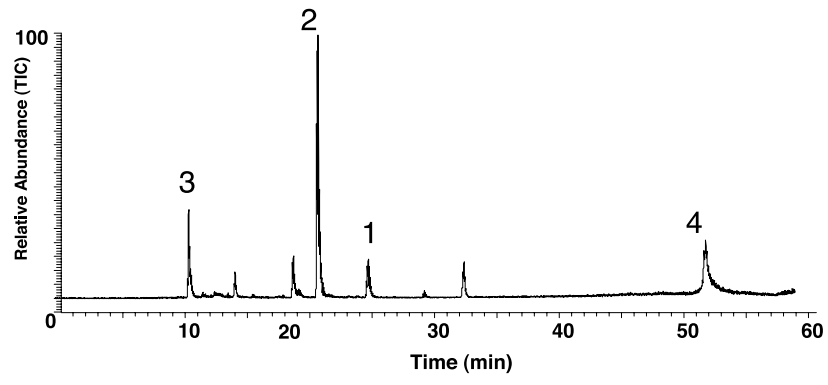

Fig. 5 Representative LC-ESI-MS total ion chromatogram of the saponin fractions from the leaves of Aralia elata.

Table 3 In-source CID data of HPLC peaks corresponding to compounds $\mathbf{1}-\mathbf{4}$ in the positive-ion mode

\begin{tabular}{cccl}
\hline & $t_{\mathrm{R}} / \mathrm{min}$ & {$[\mathrm{M}+\mathrm{Na}]^{+}(\mathrm{m} / \mathrm{z})$} & \multicolumn{1}{c}{$\mathrm{CID}(\mathrm{m} / \mathrm{z})$} \\
\hline $\mathbf{1}$ & 24 & 1127 & 965 \\
$\mathbf{2}$ & 22 & 1289 & 1127 \\
$\mathbf{3}$ & 10 & 1143 & 981,527 \\
$\mathbf{4}$ & 52 & 1143 & $1099,981,689,527$ \\
\hline
\end{tabular}

\section{HPLC/MS of compounds $\mathbf{1}-\mathbf{4}$}

Triterpenoid saponins from the leaves of Aralia elata have been extensively investigated using both positive and negative ESI$\mathrm{MS}^{\mathrm{n}}$ strategies after tedious and time-consuming isolation procedures by means of successive column chromatography. In the meantime, characteristic fragmentations of these saponins were achieved. It is now the time for us to establish a rapid and practical MS-based method for the direct identification of these saponins from crude plant extracts without any tedious separation of individual saponin compounds. It is well-known that LC-MS is a very powerful approach for the rapid identification of phytochemical constituents in crude plant extracts, ${ }^{29}$ thus avoiding a time-consuming isolation of the pure compound. HPLC-MS is also a very good complementary analytical tool for the differentiation of isomeric saponins with the same aglycone. ${ }^{23}$

HPLC-MS experiments were then employed using in-source CID. Four saponins were successfully analyzed from a complex saponin mixture extracted from leaves of Aralia elata, based on different polarities of the four saponins, resulting in different retention times with HPLC separation, as shown in Fig. 5. The HPLC-MS (in-source CID) data are listed in Table 3 . The isomeric saponins, compounds $\mathbf{3}$ and $\mathbf{4}$, were further differentiated based on different retention times and different fragmentation ions; these results are in good agreement with the structures of compounds 1-4, and the positive ESI-MS ${ }^{\mathrm{n}}$ data. Compound 2 showed a very similar structure to that of compound $\mathbf{1}$, but with one more glucose unit attached to the $\mathrm{C}-3$ terminal, exhibiting a higher polarity, and thus eluting 2 min earlier in retention time on a reverse-phase C-18 column. Compounds 3 and $\mathbf{4}$ showed tremendous differences in the retention time, because no glucose residues were attached to the $\mathrm{C}-28$ position of compound $\mathbf{4}$, which greatly reduced its polarity, resulting in much more retention time on the column than that of compound 3. Thus, a new HPLC-MS method has been successfully developed for the simultaneous analysis of these four major saponins from leaves of Aralia elata. 


\section{Conclusion}

Considering that saponins fractions from Aralia elata are very important components in this plant, and are responsible for their pharmaceutical activities, to explore a recycled source and to protect any devastating use of this valuable herbal medicine are of great significance. In the mean time, a rapid structural characterization and identification of saponins from a crude mixture of extracts from Aralia elata are in great need. By a combination of positive and negative ESI-MS ${ }^{\mathrm{n}}$ strategies, the structures of saponins from Aralia elata can be characterized more easily and rapidly. In negative ESI-MS ${ }^{\mathrm{n}}$ experiments, a series of $\mathrm{Y}$ types of ions produced allowed direct determinations of aglycones, saccharide sequences, and compositions. However, no linkage information or cross-ring ions (A and X types of ions) could be obtained. However, in positive ESI-MS ${ }^{\mathrm{n}}$ experiments, $\mathrm{Y}, \mathrm{Z}, \mathrm{B}$, and $\mathrm{C}$ types of fragment ions were yielded to provide the information about the primary sequence and branching in the sugar moieties of saponins. More importantly, the cross-ring A and $\mathrm{X}$ types of ions can provide linkage information between sugar residues. Even positive ESI-MS ${ }^{\mathrm{n}}$ can be used to differentiate isomeric saponins after the isolation of individual saponin compounds. However, the isolation of individual saponins was tedious, time- and material-consuming. To this end, a simple, fast and practical HPLC/MS method has been successfully developed for the simultaneous separation and analysis of a saponin mixture from leaves of Aralia elata for the first time. Our approach will be suitable for the rapid screening of saponins from plant extracts, or remedies based on saponin fractions from this plant. The newly developed method will also be useful in pharmaceutical, clinical, and scientific applications related to saponins extracted from this medicinal plant.

\section{References}

1. Z. G. Wang, S. J. Song, H. W. Lu, and H. Kodama, Clin. Chim. Acta, 2003, 336, 65.

2. S. Saito, J. Ebashi, and S. Sumita, Chem. Pharm. Bull., 1993, $41,1395$.

3. C. J. Shao, R. Kasai, J. D. Xu, and O. Tanaka, Chem. Pharm. Bull., 1989, 37, 311.

4. M. Yoshikawa, H. Matsuda, and E. Harada, Chem. Pharm. Bull., 1994, 42, 1354.

5. S. J. Song, N. Nakamura, C. M. Ma, M. Hattori, and S. X. $\mathrm{Xu}$, Phytochemistry, 2001, 56, 491.

6. S. J. Song, N. Nakamura, C. M. Ma, and M. Hattori, Chem. Pharm. Bull., 2000, 48, 838.
7. H. X. Kuang, H. Sun, N. Zhang, Y. Okada, and T. Okuyama, Chem. Pharm. Bull., 1996, 44, 2183.

8. J. H. Gil, J. H. Jung, K. J. Kim, M. S. Kim, and J. Hong, Anal. Sci., 2006, 22, 641.

9. D. C. van Setten, G. Zomer, G. Van de Werken, E. J. H. J. Wiertz, B. R. Leeflang, and J. P. Kamerling, Phytochem. Anal., 2000, 11, 190.

10. M. Zehl, E. Pittenauer, L. Jirovetz, P. Bandhari, B. Singh, V. K. Kaul, A. Rizzi, and G. Allmaier, Anal. Chem., 2007, 79, 8214.

11. Y. Z. Liu, F. Liang, L. J. Cui, M. Xia, L. Y. Zhao, Y. C. Yang, J. G. Shi, and Z. Abliz, Rapid Commun. Mass Spectrom., 2004, 18, 235.

12. S. Y. Liu, M. Cui, Z. Q. Liu, F. R. Song, and W. J. Mo, J. Am. Soc. Mass Spectrom., 2004, 15, 133.

13. S. Broberg, L. I. Nord, and L. Kenne, J. Mass Spectrom., 2004, 39, 691.

14. T. H. Kao, S. C. Huang, B. S. Inbaraj, and B. H. Chen, Anal. Chim. Acta, 2008, 626, 200.

15. S. Z. Ackloo, R. W. Smith, J. K. Terlouw, and B. E. McCarry, Analyst, 2000, 125, 591.

16. M. Q. Guo, F. R. Song, Y. Bai, Z. Q. Liu, and S. Y. Liu, Anal. Sci., 2002, 18, 481.

17. M. Q. Guo, F. R. Song, Z. Q. Liu, and S. Y. Liu, Anal. Chim. Acta, 2006, 557, 198.

18. F. R. Song, M. Cui, Z. Q. Liu, and S. Y. Liu, Rapid Commun. Mass Spectrom., 2004, 18, 2241.

19. Y. Wang, X. Lu, and G. Xu, J. Chromatogr., A, 2008, 1181, 51.

20. X. He, L. Z. Liu, and L. Lian, J. Chromatogr., A, 1996, 755, 127.

21. M. Careri, A. Mangia, and M. Musci, J. Chromatogr., A, 1998, 794, 263.

22. A. Raffaelli, G. Moneti, V. Mercati, and E. Toja, J. Chromatogr., A, 1997, 777, 223.

23. M. Cui, F. R. Song, Y. Zhou, Z. Q. Liu, and S. Y. Liu, Rapid Commun. Mass Spectrom., 2000, 14, 1280.

24. B. Domon and C. E. Costello, Glycoconjugate J., 1988, 5, 397.

25. S. J. Song, J. H. Li, S. X. Xu, J. C. Lu, and M. Hattori, Chin. J. Med. Chem., 2000, 38, 296.

26. X. Wang, T. Sakuma, E. Asafu-Adjaye, and G. K. Shiu, Anal. Chem., 1999, 71, 1579.

27. J. L. Wolfender, S. Rodriguez, K. Hostettmann, and W. Wagner-Redeker, J. Mass Spectrom. Rapid Commun. Mass Spectrom., 1995, Special Issue, 35.

28. X. G. He, J. Chromatogr., A, 2000, 880, 203.

29. T. Madl, H. Sterk, M. Mittelbath, and G. N. Rechberger, $J$. Am. Soc. Mass Spectrom., 2006, 17, 795. 